\title{
OPTIMALISASI POSISI HEATER DAN COOLER TERHADAP PERUBAHAN KONDISI SUHU PADA INKUBATOR TETAS PENETAS TELUR
}

\author{
Noor Yulita Dwi Setyaningsih \\ Fakultas Teknik, Program Studi Teknik Elektro \\ Universitas Muria Kudus \\ Email: noor.yulita@umk.ac.id \\ Adib Nurul Mustofa \\ Fakultas Teknik, Program Studi Teknik Elektro \\ Universitas Muria Kudus \\ Email: adibnmustofa@gmail.com
}

\begin{abstract}
ABSTRAK
Dalam kondisi alamiah seekor induk ayam akan selalu mengerami telurnya dalam proses penetasan. Hal ini mengartikan bahwa, induk ayam menjaga konsistensi dari kondisi suhu sekitar telur-telurnya agar tetap pada kondisi yang selalu hangat. Proses alamiah ini yang kemudian dikembangkan logikanya menggunakan teknologi elektronika, dengan menciptakan suatu inkubator penetas telur. Teknologi ini muncul terkait dari kebutuhan komsumsi daging ayam yang meningkat, jika hanya mengandalkan proses alamiah maka kebutuhan tidak tercukupi. Pada kasus ini, suhu merupakan salah satu faktor penting yang memiliki peranan pada fungsi inkubator penetas telur. Inkubator penetas telur harus memiliki kondisi suhu yang merata dan stabil, dengan suhu setting point diantara $37^{\circ} \mathrm{C}-39^{\circ} \mathrm{C}$. Dengan kebutuhan tersebut sehingga dibutuhkan suatu proses pendistribusian udara panas yang cepat dan merata. Proses pendistribusian udara panas yang merata dan cepat membutuhkan posisi aktuator heater dan cooler yang tepat. Penempatan heater dan cooler mempengaruhi waktu settling time dari sistem dan kestabilan sistem, semakin cepat settling time yang didapatkan maka alat semakin optimal. Dari berbagai komposisi penempatan heater dan cooler yang telah dilakukan, didapatkan bahwa posisi lampu di dinding inkubator dengan kipas diatas lampu, dengan masing-masing daya lampu sebesar 5 watt adalah posisi yang optimal. Dengan respon sistem yang dimiliki dari posisi ini yaitu : $\mathrm{Td}=5$ menit, $\mathrm{Tr}=10$ menit dan $\mathrm{Ts}$ 11 menit.
\end{abstract}

Kata kunci: lampu; kipas; posisi; penetas telur; pemerataan suhu.

\begin{abstract}
In natural conditions, a mother will always incubate her eggs in the hatching process. This means that, the mother hen keeps the consistency of the temperature conditions around her eggs to remain in a condition that is always warm. This natural process which was later developed logically used electronic technology, by creating an egg incubator. This technology appears related to the increased consumption of chicken meat, if it only relies on natural processes, the needs are not fulfilled. In this case, temperature is one of the important factors that have a role in the function of the egg incubator. The egg incubator must have even and stable temperature conditions, with the temperature setting point between $37^{\circ} \mathrm{C}-39^{\circ} \mathrm{C}$. With these needs, a fast and even distribution of hot air is needed. The even and fast distribution of hot air requires the right position of the heater and cooler actuator. Placement of heater and cooler affects the time of settling time of the system and system stability, the faster the settling time is obtained, the more optimal the tool. From the various compositions of heater and cooler placement that have been done, it was found that the position of the lamp on the incubator wall with the fan above the lamp, with each lamp power of 5 watts is the optimal position. With the system response that is held from this position, namely: $T D=5$ minutes, $\operatorname{Tr}=10$ minutes and $T$ s 11 minutes.
\end{abstract}

Keywords: lamps; fan; position; egg incubator; temperature equalization.

\section{PENDAHULUAN}

Proses penetasan telur ayam dibedakan menjadi dua, yaitu proses alamiah dan buatan. Penetasan telur secara ilmiah dilakukan oleh induk ayam dengan cara dierami, serta penetasan telur buatan bergangtung pada telur tetas, mesin tetas dan operator [1]. Inkubator penetas telur ayam merupakan salah satu aplikasi teknologi yang menggunakan logika proses pengeraman induk ayam secara alami. Salah 
satu faktor penting untuk mencapai kondisi inkubator penetas telur adalah suhu. Suhu berperan penting untuk menentukan kesuksesan hasil tetasan telur. Kisaran suhu ideal untuk penetasan telur ayam berkisar antara $36^{\circ} \mathrm{C}-40^{\circ} \mathrm{C}$ atau dapat diseragamkan pada suhu antara $37^{\circ} \mathrm{C}-39^{\circ} \mathrm{C}$ [2][3][4]. Kesegaran udara pada inkubator penetas telur mempengaruhi dari perkembangan embrio. Embrio yang berkembang akan membutuhkan banyak oksigen dan membutuhkan gas $\mathrm{CO}_{2}$. Kedua konsentrasi gas tersebut mempengaruhi dari daya tetas yang dihasilkan. Kelebihan dan kekurangan oksigen mempengaruhi penurunan daya tetas telur. Dengan adanya ventilasi dan sirkulasi udara yang baik atau pemerataan suhu yang baik akan menjaga kesegaran udara pada ruang penetas telur [5]. Inkubator penetas telur ayam juga dapat dimanfaatkan bagi petani yang bergerak dibidang peternakan khususnya petani peternak ayam pedaging dan ayam petelur. Setiap tahunnya data statistik mencatat kebutuhan masyarakat akan daging ayam terus mengalami peningkatan yang cukup signifikan. Dengan kondisi ini secara tidak langsung akan memberikan dampak positif kepada peternak ayam. Yang dimana peternak akan berupaya untuk meningkatkan usaha pembibitan ayamnya. Jika hanya mengandalkan proses alamiah, untuk mengejar kebutuhan konsumen akan sedikit membutuhkan waktu yang lama [6].

Beberapa penelitian yang telah ada yaitu terpusat pada pemilihan kendali yang digunakan. Dini ismawati telah melakukan penelitian terkait inkubator penetas telur menggunakan model kendali fuzzy, pada penelitian ini terfokuskan pada pengaruh dari jumlah membership function yang digunakan untuk kendali suhu ruangan inkubator. Aktuator yang digunakan adalah kipas yang berfungsi sebagai pendingin dan lampu sebagai pemanas. Pada penelitian ini posisi aktuator pemanas dan pendingin tidak di perhatikan dan posisi sensor suhu yang digunakan berada dibawah pemanas [2]. Metode fuzzy logic juga digunakan oleh suprapto dalam penelitian tentang mesin penetas telur [7]. Sofyan Shafiudin juga melakukan penelitian yang sama di bidang inkubator penetas telur. Sofyan melakukan pengendalian suhu inkubator penetas telur menggunakan metode kendali PID [8], sistem kerja kendali PID juga digunakan pada pengendalian inkubator yang dimanfaatkan untuk pengendalian inkubator bayi[9].

Jenis aktuator yang digunakan pada penelitian ini ada dua macam yaitu lampu pijar sebagai pemanas dan kipas sebagai cooler serta sirkulasi udara. Untuk pemilihan jenis pemanas lampu pijar mengacu pada penelitian sebelumnya yang telah melakukan penelitian terkait pemilihan lampu sebagai pemanas. Lampu pijar memiliki hubungan yang linier dengan suhu yang dihasilkan. Semakin besar daya dari lampu pijar, maka suhu yang dihasilkan juga mengikuti [10].

Dengan banyaknya penelitian terkait inkubator penetas telur yang terfokuskan pada metode pengendaliannya, dan belum ada yang terfokuskan pada pengaruh posisi atau letak dari aktuator pemanas dan pendingin agar kondisi suhu yang ada didalam ruang inkubator bayi merata. Posisi pemanas dengan pendingin atau untuk sirkulasi udara sangat berpengaruh pada mekanisme pendistribusian suhu di dalam ruangan supaya merata dan stabil. Dengan kondisi yang seperti ini, maka penelitian ini terfokuskan untuk mengetahui pengaruh dari posisi lampu dan kipas terhadap kondisi suhu yang merata pada ruang inkubator penetas telur.

\section{METODOLOGI PENELITIAN}

Beberapa tahap metode penelitian yang digunakan terdiri dari study literatur, dimana tahap ini mengumpulkan data dan bahan dari penelitian sebelumnya yang berkaitan dengan penelitian ini, kemudian setelah mendapatkan bahan dari penelitian sebelumnya tahap berikutnya adalah melakukan perancangan hardware dan software. Dilanjutkan untuk pembuatan hardware dan software yang kemudian dilakukan pengujian dan pengambilan data. Perancangan inkubator penetas telur menggunakan bahan papan triplek dengan design bok inkubator sebagai berikut: panjang bok $50 \mathrm{~cm}$, tinggi $40 \mathrm{~cm}$, lebar $35 \mathrm{~cm}$. Tampilan design bok inkubator seperti Gambar 1.

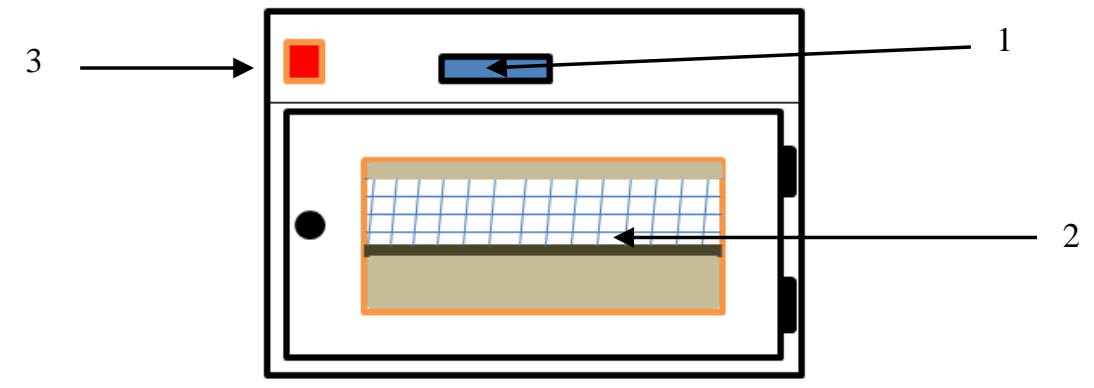

Keterangan Gambar 1 :

Gambar 1. Design Bok Penetas Telur

a) LCD

b) Rak Telur 
c) Saklar on/off

Setelah membuat sesuai dengan perancangan dari prototipe inkubator penetas telur, selanjutnya adalah melakukan realisasi dari perancangan hardware yang digunakan seperti pada Gambar 2.

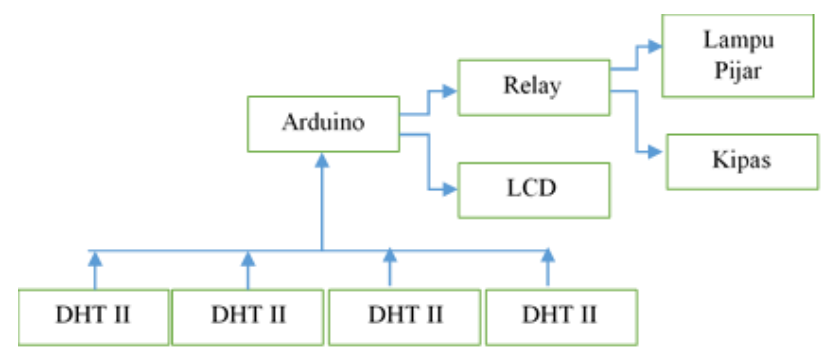

Gambar 2. Perancangan Hardware

Dari Gambar 2 dapat dilihat komponen hardware yang digunakan pada penelitian ini, diantaranya adalah sensor DHT 11 sebanyak 4 buah, kemudian Arduino yang digunakan sebagai kendali dan relay untuk aktuator penggerak dari heater (lampu pijar) dan cooler (kipas), serta LCD untuk menampilakan hasil. Sistem kerja dari hardware ini dimana sensor akan membaca data suhu ruangan yang kemudian data itu akan dikirimkan dan dibaca oleh arduino, data dari ke empat sensor akan dirata-rata dan hasilnya dibandingkan dengan parameter setting point yang digunakan, dimana dalam penelitian ini nilai setting point suhu yang digunakan adalah $38^{\circ} \mathrm{C}$. Setelah proses perbandingan data antara nilai present value (nilai pembacaan sensor) dengan nilai setting point (nilai parameter $38^{\circ} \mathrm{C}$ ), berikutnya arduino akan mengaktifkan aktuator berupa driver relay. Relay ini akan bergerak ke posisi NO ataupun NC sesuai perintah arduino untuk mengaktifkan ataupun mengnonaktifkan dari lampu pijar maupun kipas. Sedangkan data suhu yang didapat tadi akan ditampilkan pada LCD. Untuk logika kendali dari penelitian ini, dimana saat nilai PV < SP maka aktuator pemanas dan pendingin akan aktif dan saat nilai PV > SP maka aktuator pemanas akan tidak aktif.

Sistem kendali ini dirancang untuk mengetahui pengaruh dari posisi pemanas dan pendingin terhadap hasil pemerataan suhu pada ruang inkubator penetas telur. Sensor yang digunakan pada penelitian ini ada empat buah, untuk mengetahui kondisi suhu yang ada dalam ruangan merata atau tidak, mengetahui kondisi suhu ruangan terjadi perbedaan yang signifikan atau tidak. Pemerataan suhu pada ruang inkubator bayi akan berdampak pada proses tetas dari telur. Untuk mengetahui pengaruh posisi dari pemanas dan pendingin terhadap kondisi suhu, maka kendali yang digunakan pada penelitian ini masih kendali on/off.

\section{HASIL DAN PEMBAHASAN}

Peneliltian yang dilakukan untuk uji coba posisi pemanas dan pendingin yang sering digunakan pada penelitian sebelumnya, dan melakukan perbandingan kondisi suhu yang dihasilkan dari posisi pemanas dan pendingin yang digunakan. Penelitian yang dilakukan memanfaatkan dua posisi peletakan pemanas dan pendingin yaitu, posisi lampu yang berada di samping dinding bok inkubator serta posisi kipas berada diatas lampu, dan posisi yang kedua adalah posisi lampu berada di atap bok inkubator dengan kipas berada di depan lampu. Lampu yang digunakan adalah jenis lampu pijar, mengambil dari penelitian sebelumnya yang sudah melakukan penelitian tentang jenis lampu yang baik untuk pemanas pada inkubator. Ada dua jenis lampu pijar yang digunakan pada penelitian ini, yaitu lampu pijar 5 watt dan 15 watt dengan jumlah lampu pijar yang digunakan 4 buah. Penelitian juga memperhitungkan tempat atau posisi sensor yang digunakan, ada 4 sensor yang digunakan dan ada dua posisi yang digunakan yang pertama sensor diletakkan pada dinding bok inkubator dan posisi kedua sensor diletakkan pada rak telur.
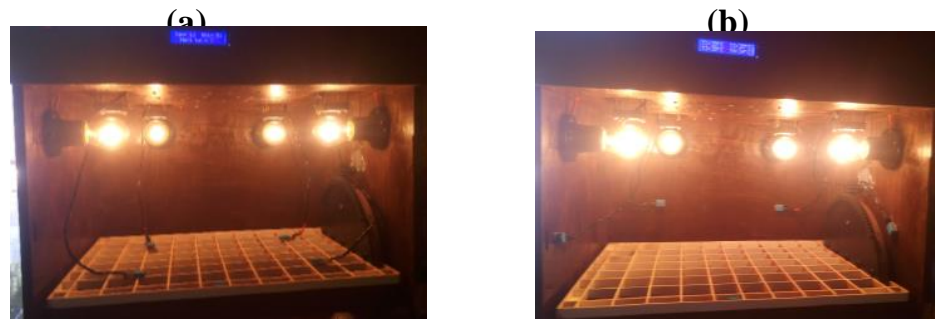

Gambar 3. Posisi Uji Satu (A) Sensor Di Rak Telur, (B) Sensor Di Dinding Inkubator 
Gambar 3 merupakan posisi uji pertama pada penelitian ini, dimana posisi lampu berada di samping dinding inkubator dengan kipas berada diatas lampu. Lampu digunakan sebagai pemanas, serta kipas sebagai pendingin sekaligus untuk sirkulasi. Sensor DHT II diletakkan pada rak telur. Jumlah lampu, kipas dan sensor DHT II yang digunakan sejumlah 4 buah. Pada posisi uji yang pertama akan dilakukan dua pengujian pada posisi sensor DHT II yang berbeda, dimana posisi pertama adalah sensor diletakkan di rak penempatan telur dan posisi kedua sensor diletakkan di dinding inkubator.

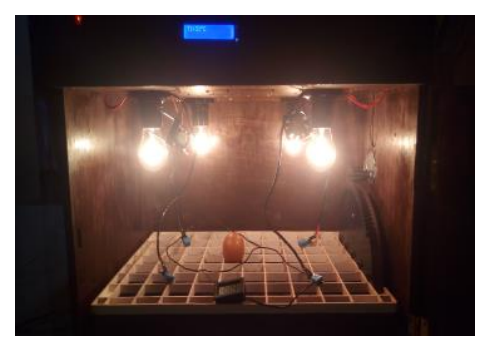

(a)

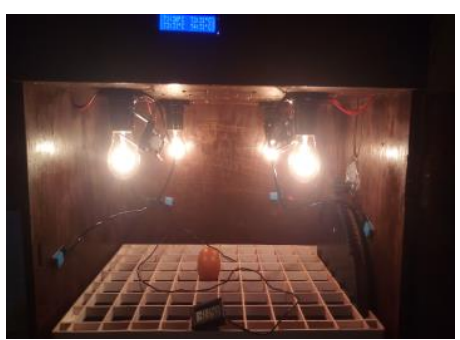

(b)

Gambar 4. Posisi Uji Dua (a) Sensor di rak telur, (b) Sensor di dinding inkubator

Gambar 4 merupakan posisi uji kedua dari penelitian ini, dimana posisi lampu berada di bagian atas inkubator, dalam hal ini berada diatap inkubator. Pengujian juga dilakukan dua kondisi, dimana kondisi pertama sensor diletakkan pada rak tempat telur dan kondisi kedua sensor berada di dinding inkubator. Kedua posisi yang dilakukan pengujian bertujuan untuk mencari posisi yang paling optimal. Nilai Setting Point yang digunakan adalah $38^{\circ} \mathrm{C}$, batas kestabilan dari sistem yang digunakan adalah $\pm 5 \%$ dari SP yaitu antara $36,1^{\circ} \mathrm{C}-39,9^{\circ} \mathrm{C}$.

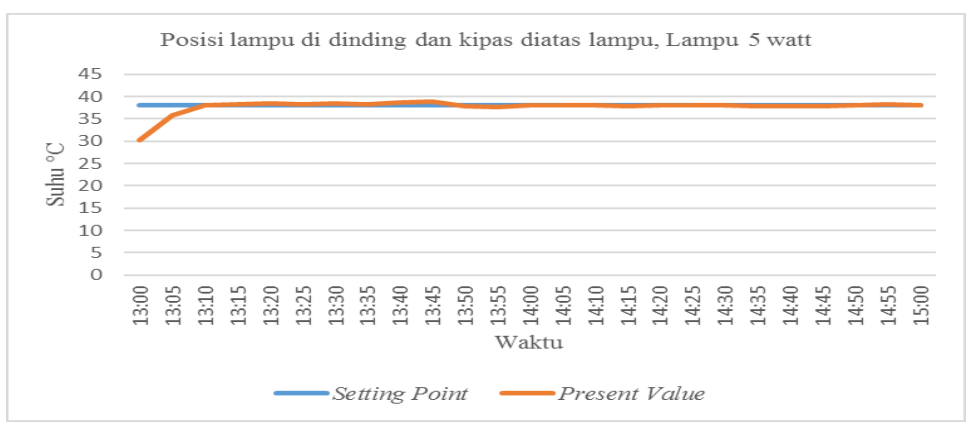

\section{Gambar 5. Hasil Kendali Suhu Dengan Posisi Lampu 5 Watt di Dinding Inkubator}

Gambar 5 merupakan hasil kendali suhu ruang inkubator penetas telur menggunakan lampu pijar 5 watt, dengan posisi lampu berada disamping dinding inkubator dan lampu berada diatas lampu. Data diambil saat siang hari dari jam 13.00 sampai 15.00 dengan suhu luar ruang inkubator $29^{\circ} \mathrm{C}$. Pengambilan data dicuplik setiap 5 menit. Dari data yang didapatkan, dilihat bahwa waktu yang dibutuhkan untuk mencapai kondisi steady state selama 10 menit.

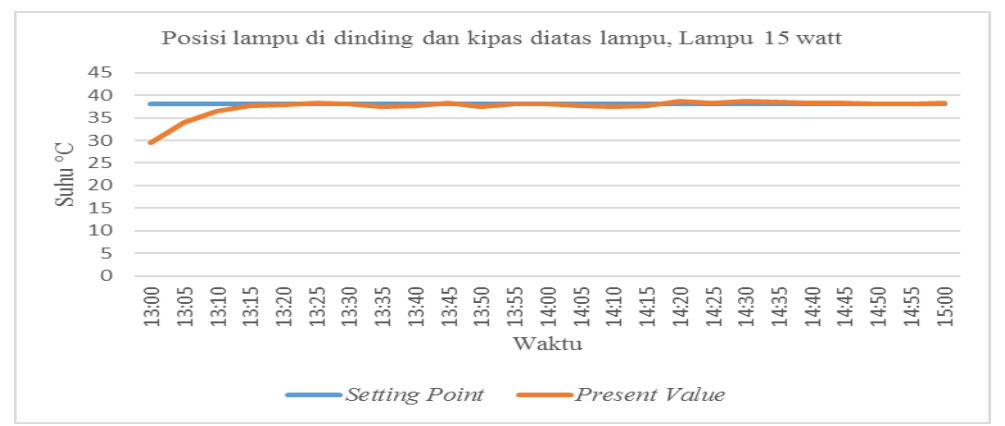

\section{Gambar 6. Hasil Kendali Suhu dengan Posisi Lampu 15 Watt di Dinding Inkubator}

Gambar 6 merupakan hasil kendali suhu ruang inkubator penetas telur menggunakan lampu pijar 15 watt, dengan posisi lampu berada disamping dinding inkubator dan lampu berada diatas lampu. Data diambil saat siang hari dari jam 13.00 sampai 15.00 dengan suhu luar ruang inkubator $29^{\circ} \mathrm{C}$. 
Pengambilan data dicuplik setiap 5 menit. Dari data yang didapatkan, dilihat bahwa waktu yang dibutuhkan untuk mencapai kondisi steady state selama 15 menit

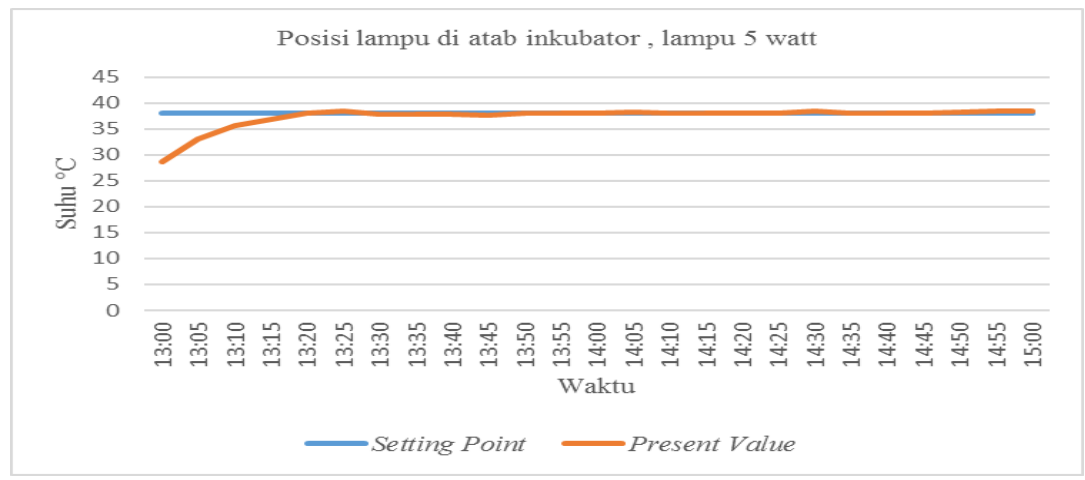

Gambar 7. Hasil Kendali Suhu dengan Posisi Lampu 5 Watt diatas (Atab) Inkubator

Gambar 7 merupakan hasil dari pengendalian suhu dengan penggunaan lampu pijar 5 watt. Posisi lampu berada diatab inkubator. Pengambilan data juga diambil pada waktu yang sama yaitu pukul 13.00 sampai 15.00 WIB. Pada hasil data didapatkan waktu untuk mencapai ke kondisi steady state selama 17 menit.

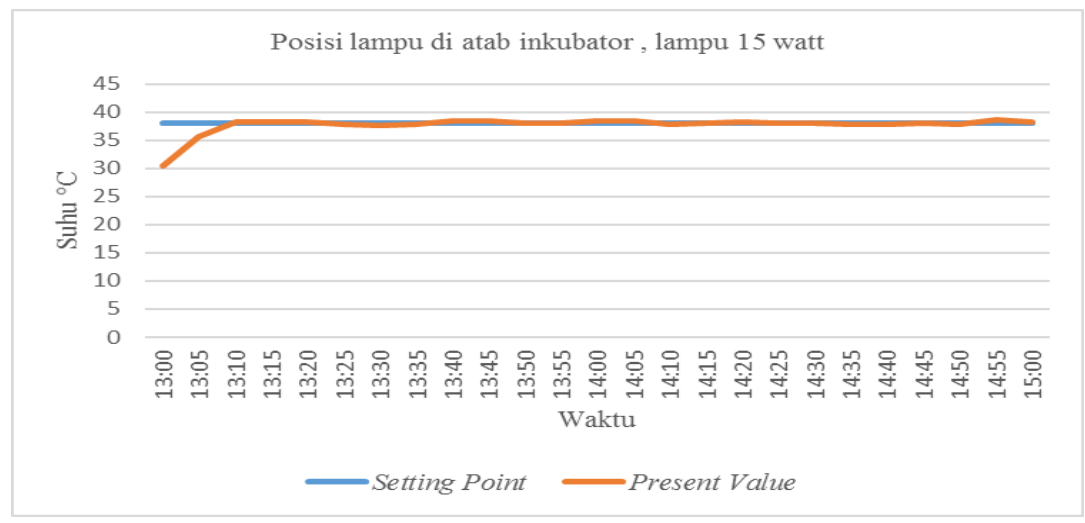

Gambar 8. Hasil Kendali Suhu dengan Posisi Lampu 15 watt diatas (atab) Inkubator

Gambar 8 merupakan hasil dari pengendalian suhu dengan penggunaan lampu pijar 15 watt. Posisi lampu berada diatab inkubator. Pengambilan data juga diambil pada waktu yang sama yaitu pukul 13.00 sampai 15.00 WIB. Pada hasil data didapatkan waktu untuk mencapai ke kondisi steady state selama 11 menit.

Dari ke empat data yang diperoleh, posisi lampu yang berada di dinding inkubator dengan pemanfaatan lampu pijar 5 watt memiliki data pemerataan suhu yang lebih baik dibandingkan dengan ketiga posisi yang lain. Untuk posisi lampu yang berada diatab inkubator dengan besar watt yang digunakan perlampu adalah 15 watt, terlihat stabil tapi pemerataan yang dihasilkan tidak baik, karena tidak adanya kipas yang berfungsi untuk mensirkulasikan udara panas pada ruang inkubator.

\section{KESIMPULAN}

Dari penelitian yang telah dilakukan terkait pemilihan posisi dari pemanas dan pendingin yang digunakan untuk pemerataan suhu ruang inkubator penetas telur adalah posisi lampu yang diletakkan pada dinding inkubator, dengan jumlah lampu yang digunakan sebanyak 4 buah lampu dengan penggunaan daya yang digunakan masing-masing lampu 5watt. Posisi kipas berada diatas lampu. Dengan respon sistem yang dihasilkan sebagai berikut: $\mathrm{Td}=5$ menit, $\mathrm{Tr}=10$ menit dan $\mathrm{Ts} 11$ menit.

\section{DAFTAR PUSTAKA}

[1] A. Goeritno, K. Aldiansyah, M. Aziz, A. Eko, K. Pramuko, and H. Hendrawan, "Implementasi Sistem Kontrol Berbasis Arduino UNO R3 Untuk Sistem Penetasan Telur Ayam,” in Seminar Nasional Inovasi Dan Aplikasi Teknologi Di Industri 2017, 2017, pp. 1-10.

[2] D. Ismawati, D. Syauqy, and B. H. Prasetio, "Perbandingan Jumlah Membership Dan Model Fuzzy 
Terhadap Perubahan Suhu Pada Inkubator Penetas Telur," J. Pengemb. Teknol. Inf. dan Ilmu Komput., vol. 1, no. 6, pp. 476-485, 2017.

[3] I. Nurhadi and E. Puspita, "Rancang Bangun Mesin Penetas Telur Omtomatis Berbasis Mikrokontroler ATMega8 Menggunakan Sensor SHT 11," 2009.

[4] I. Larasati, "Rancang Bangun Sistem Kendali Suhu Pada Penetas Telur Ayam Berbasis Java Menggunakan Fuzzy Logic Control,” 2017.

[5] Y. Gunardi, "Perancangan dan Pembuatan Penetas Telur Berbasis Arduino Dumilanove," in Prosiding SNPPTI, 2012, vol. 7, no. 1, pp. 272-277.

[6] D. Dhanny Jufril, Darwison, Budi Rahmadya, "Implementasi Mesin Penetas Telur Ayam Otomatis Menggunakan Metoda Fuzzy Logic Control,” in Seminar Nasional Sains dan Teknologi, 2015, no. November, pp. 1-6.

[7] E. S. Suprapto, Anang Tjahjono, "Rancang Bangun Mesin Penetas Telur Ayam Berbasis Mikrokontroler Dengan Fuzzy Logic Controller."

[8] N. K. Sofyan Shafiudin, "Sistem Monitoring Dan Pengontrolan Temperatur Pada Inkubator Penetas Telur Berbasis PID,” Jur. Tek. Elektro, vol. 6, no. 3, pp. 175-184, 2017.

[9] I. A. R. Noor Yulita Dwi Setyaningsih, "Kendali suhu inkubator bayi menggunakan pid," SIMETRIS, vol. 7, no. 2, pp. 489-494, 2016.

[10] N. Yulita, D. Setyaningsih, and O. Wahyunggoro, "Pemilihan lampu sebagai pemanas pada inkubator bayi," in Seminar Nasional Teknologi Informasi dan Multimedia 2015, 2015, pp. 6-8. 